\title{
Self-Reported Changes in Thirst and Alertness during Variable Prescribed Fluid Intake
}

\author{
Hillary A. Yoder ${ }^{a, b}$ Ainsley E. Huffman ${ }^{b, c}$ Shane McCullough ${ }^{b}$ \\ Evan C. Johnson ${ }^{b}$ \\ aExercise Physiology Lab, University of Alabama, Tuscaloosa, AL, USA; ${ }^{b}$ Human Integrated Physiology Laboratory, \\ University of Wyoming, Laramie, WY, USA; 'Population Health Science, University of Utah, Salt Lake City, UT, USA
}

\section{Keywords}

Water intake $\cdot$ Euhydration $\cdot$ Thirst

\begin{abstract}
Background: Maintaining euhydration is beneficial for health, safety, and physical performance [1]; however, it may also improve subjective feelings [2, 3]. Objective: The aim of this study was to evaluate the relationship between changes in self-reported thirst and alertness in people undergoing changes in drinking water volume. Methods: Subjects (mean $\pm \mathrm{SD})\left(n=115,59\right.$ males, $32 \pm 10$ years; $\left.24.6 \pm 4.4 \mathrm{~kg} \cdot \mathrm{m}^{-2}\right)$ visited the lab 3 times over 10 days: $V 1$, a baseline visit prior to participants were drinking ad libitum; V2, following 3 days of fluid restriction $\left(1 \mathrm{~L} \cdot \mathrm{d}^{-1}, 250 \mathrm{~mL}\right.$ was consumed in the morning prior to the visit); and V3, the morning following a prescribed increase in water intake. The increase in water intake at V3 varied by group assignment: control group (CON) maintained $250 \mathrm{~mL}$, while LOW and HIGH groups ( $n=45$ each) consumed $496 \pm 82 \mathrm{~mL}$ and $878 \pm 125 \mathrm{~mL}$, respectively. At each visit, subjects indicated on an open-ended visual analog scale (VAS) how thirsty and alert they felt and were measured in millimeters ( $\mathrm{mm})$. Four, two-way ANOVAs (group $\times$ visit) for change in thirst and alertness between V1V2 and V2-V3 were completed. A repeated-measures correlation $\left(r_{\mathrm{rm}}\right)$ procedure was completed for change in alertness
\end{abstract}

karger@karger.com www.karger.com/anm

Karger $\stackrel{\text { ' }}{5}$
(C) 2022 The Author(s)

Published by S. Karger AG, Basel

This article is licensed under the Creative Commons Attribution 4.0 International License (CC BY) (http://www.karger.com/Services/ OpenAccessLicense). Usage, derivative works and distribution are permitted provided that proper credit is given to the author and the original publisher. and thirst from V1 to V2 and V2 to V3 [4]. The study was approved by the University of Wyoming's Institutional Review Board (protocol \#20160524EJ01208), and all subjects provided written informed consent. Results: Groups were similar at baseline (V1) for fluid intake, thirst, and alertness (all $p \geq$ 0.17 ). Fluid restriction (V2) resulted in a main effect of visit for thirst and alertness (both $p<0.01$ ), with no main effect of group. Thirst increased $(35 \pm 35 \mathrm{~mm})$ and alertness decreased $(-19 \pm 31 \mathrm{~mm})$ from $\mathrm{V} 1$ to $\mathrm{V} 2$. The prescribed increase in water intake (V3) revealed a significant interaction of visit and group for thirst and alertness (both $p<0.01$ ) (Table 1). Independent-samples $t$ tests with a Bonferroni correction revealed that HIGH reduced thirst $(-38 \pm 37 \mathrm{~mm})$ and increased alertness $(18 \pm 25 \mathrm{~mm})$, while no change was observed for LOW (thirst, $-7 \pm 37 \mathrm{~mm}$; alertness $-1 \pm 24 \mathrm{~mm}$ ) and CON (thirst, $-6 \pm 23 \mathrm{~mm}$; alertness $0 \pm 23 \mathrm{~mm}$; all $p<0.01$ ) (Fig. 1). There was no difference between LOW and CON (both $p>$ 0.92). Repeated-measures correlation analysis revealed an inverse relationship between change in alertness and thirst $\left(r_{\text {rm }}[114]=-0.53,95 \% \mathrm{Cl}[-0.65,-0.38], p<0.01\right)$. Conclusion: A reduction in water intake resulted in an increase in thirst and decrease in alertness. Following 3 days of fluid restriction, $750-1,000 \mathrm{~mL}$ of water intake was needed to decrease thirst and increase alertness. Overall, an inverse relationship was observed between self-reported thirst and alertness.

(c) 2022 The Author(s)

Published by S. Karger AG, Basel 


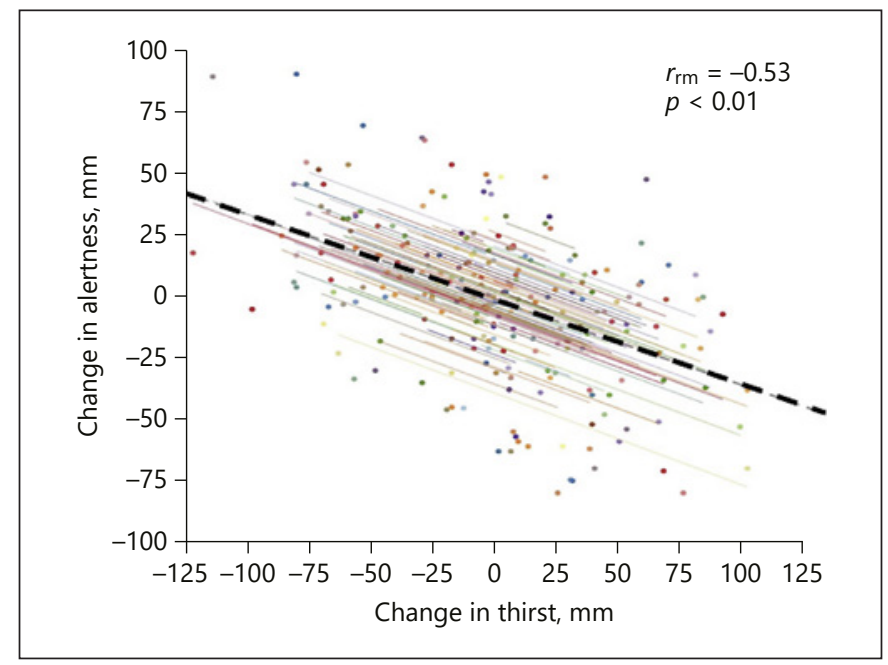

Fig. 1. Repeated measures correlation for self-reported change in thirst and alertness from V1 to V2 and from V2 to V3 $\left(r_{\mathrm{rm}}=-0.53\right.$, $p<0.01)$. Black dashed line represents overall correlation.

\section{Statement of Ethics}

The study was approved by the University of Wyoming's Institutional Review Board (protocol \#20160524EJ01208) and all subjects provided written informed consent.

\section{Conflict of Interest Statement}

E.C.J. received this grant and was partially funded during his graduate studies by similar grants from Danone Research. H.A.Y. has received speakers fees from Danone Research.
Table 1. Change in thirst and alertness from visit 1 (V1) to visit 2 (V2) and V2 to visit 3 (V3) in millimeter

\begin{tabular}{llllll}
\hline Group & \multicolumn{1}{l}{$\Delta \mathrm{V} 1-\mathrm{V} 2$} & & \multicolumn{2}{l}{$\Delta \mathrm{V} 2-\mathrm{V} 3$} & \\
\cline { 2 - 3 } \cline { 5 - 6 } & Thirst, $\mathrm{mm}$ & Alertness, $\mathrm{mm}$ & & Thirst, $\mathrm{mm}$ & Alertness, $\mathrm{mm}$ \\
\hline CON & $35 \pm 23$ & $-21 \pm 23$ & & $-6 \pm 23$ & $0 \pm 23$ \\
LOW & $34 \pm 35$ & $-15 \pm 33$ & & $-7 \pm 37$ & $-1 \pm 24$ \\
HIGH & $37 \pm 41$ & $-21 \pm 33$ & & $-38 \pm 37^{* *}$ & $18 \pm 25^{* *}$ \\
\hline
\end{tabular}

** Indicates significant difference from CON and LOW.

\section{Author Contributions}

E.C.J. was the principal investigator and developed the project. H.A.Y., A.E.H., and S.M. completed the data collection and data entry. E.C.J. and H.A.Y. completed the statistical analysis and wrote the abstract with input from A.E.H. and S.M.

\section{Data Availability Statement}

Data are not available because we are working on a manuscript based on this project and want to keep the data confidential for the time being.

\section{Funding Sources}

This Investigation was funded by Danone Research.

\section{References}

Self-Reported Changes in Thirst and Alertness
1 Convertino VA, Armstrong LE, Coyle EF, Mack GW, Sawka MN, Senay LC Jr, et al. American College of Sports Medicine position stand. Exercise and fluid replacement. Med Sci Sports Exer. 1996;28(1):i-vii.

2 Ganio MS, Armstrong LE, Casa DJ, McDermott BP, Lee EC, Yamamoto LM, et al. Mild dehydration impaits cognitive performance and mood of men. Br J Nutr. 2011;106(10): 1535-43.
3 Shirreffs SM, Merson SJ, Fraser SM, Archer DT. The effects of fluid restriction on hydration status and subjective feelings in man. $\mathrm{Br}$ J Nutr. 2004;91(6):951-8.

4 Bakdash JZ, Marusich LR. Repeated measures correlation. Front Psychol. 2017;8:456. 